\title{
FOURTH STATUS REPORT: TESTING OF AGED SOFTWOOD FIBERBOARD MATERIAL FOR THE 9975 SHIPPING PACKAGE
}

\author{
W. L. Daugherty \\ Savannah River National Laboratory \\ Materials Science \& Technology
}

Publication Date: February 2013

Savannah River Nuclear Solutions

Savannah River Site

Aiken, SC 29808

This document was prepared in conjunction with work accomplished under Contract No. DE-AC09-08SR22470 with the U.S. Department of Energy. 


\section{DISCLAIMER}

This work was prepared under an agreement with and funded by the U.S. Government. Neither the U. S. Government or its employees, nor any of its contractors, subcontractors or their employees, makes any express or implied: 1 . warranty or assumes any legal liability for the accuracy, completeness, or for the use or results of such use of any information, product, or process disclosed; or 2. representation that such use or results of such use would not infringe privately owned rights; or 3 . endorsement or recommendation of any specifically identified commercial product, process, or service. Any views and opinions of authors expressed in this work do not necessarily state or reflect those of the United States Government, or its contractors, or subcontractors. 
Fourth Status Report: Testing of Aged Softwood Fiberboard Material for the 9975 Shipping Package

\section{APPROVALS:}

W. L. Daugherty

Date

Author, Materials Science and Technology

T. E. Skidmore

Date

Technical Review, Materials Science and Technology

K. A. Dunn

Date

Pu Surveillance Program Lead, Materials Science and Technology

G. T. Chandler

Manager, Materials App \& Process Tech

Date

E. R. Hackney

Date

NMM Engineering

\section{REVIEWS:}

D. R. Leduc

Date

Savannah River Packaging Technology 


\section{Revision Log}

Document No. SRNL-TR-2013-00016 Rev. No. 0

Document Title Fourth Status Report: Testing of Aged Softwood Fiberboard Material for the 9975 Shipping Package

Rev. \# Page \# Description of Revision Date

$0 \quad$ all $\quad$ Original document

$3 / 5 / 13$ 


\section{Summary}

Samples have been prepared from a 9975 lower fiberboard subassembly fabricated from softwood fiberboard. Physical, mechanical and thermal properties have been measured following varying periods of conditioning in each of several environments. These tests have been conducted in the same manner as previous testing on cane fiberboard samples.

Overall, similar aging trends are observed for softwood and cane fiberboard samples, with a few differences. Some softwood fiberboard properties tend to degrade faster in elevated humidity environments, while some cane fiberboard properties degrade faster in the hotter dry environments. As a result, it is premature to assume both materials will age at the same rates, and the preliminary aging models developed for cane fiberboard might not apply to softwood fiberboard. However, it is expected that both cane and softwood fiberboard assemblies will perform satisfactorily in conforming packages stored in a typical KAMS environment for up to 15 years. Aging and testing of softwood fiberboard will continue and additional data will be collected.

Post-conditioning data have been measured on samples from a single softwood fiberboard assembly, and baseline data are also available from a limited number of vendor-provided samples. This provides minimal information on the possible sample-to-sample variation exhibited by softwood fiberboard. Data to date are generally consistent with the range seen in cane fiberboard, but some portions of the data trends are skewed toward the lower end of that range. Further understanding of the variability of softwood fiberboard properties will require testing of additional material.

\section{Background}

Cane fiberboard wall sheathing is specified for thermal insulation and impact resistance in 9975 shipping packages. Softwood fiberboard manufactured by Knight-Celotex was approved as an acceptable substitute for transportation in 2008. Data in the literature [1] show a consistent trend in thermal properties of fiberboard as a function of temperature, density and/or moisture content regardless of material source. Thermal and mechanical properties were measured for un-aged softwood fiberboard samples, and found to be sufficiently similar to those of un-aged cane fiberboard to support the acceptance of 9975 packages with softwood fiberboard overpack into KAMS for storage. The continued acceptability of aged softwood fiberboard to meet KAMS storage requirements was the subject of subsequent activities.

This is an interim status report for experiments carried out per Task Technical Plan WSRC-TR2008-00024 [2], which is part of the comprehensive 9975 package surveillance program [3]. The primary goal of this task is to validate the preliminary assessment that Knight-Celotex softwood fiberboard is an acceptable substitute for cane fiberboard in the 9975 shipping package overpack, and to verify whether the long-term performance of these two materials in a storage environment is comparable. 


\section{Experimental Method}

A lower fiberboard subassembly fabricated from softwood fiberboard for use in a 9975 shipping package was obtained from KAMS. Samples were removed from this subassembly for conditioning and testing to track the potential degradation in physical, thermal and mechanical properties. Samples were initially aged in 4 environments.

- 250F oven (nominal humidity of $\sim 1 \% \mathrm{RH}$ )

- 215F oven (nominal humidity of $\sim 1 \% \mathrm{RH}$ )

- 185F oven (nominal humidity of $\sim 2 \% \mathrm{RH}$ )

- 185F, 30\%RH environmental chamber

Additional samples began aging in 2 additional environments in 2011.

- 160F, 50\%RH environmental chamber

- 125F, 70\%RH environmental chamber

The sample configurations and test methodologies are the same as used for aging and testing cane fiberboard samples [4, 5]. Samples for physical property measurements are approximately 2 inch cubes, and receive periodic measurement of weight and dimensions. Two of these samples are conditioning in each of the 6 environments. Samples for compression testing are also approximately 2 inch cubes. These samples were placed in 5 of the environments (all environments except $215 \mathrm{~F}$ oven). A few of these samples are removed periodically for testing. Since the compression test is destructive, these samples are not returned to the conditioning environment. Several additional compression samples were added to each of the original environments in December 2009 to provide replicate data points and longer exposures. A few compression samples currently remain in their conditioning environment.

Testing for thermal properties includes both thermal conductivity and specific heat capacity. Thermal conductivity samples are approximately $7 \times 7 \times 1.3$ inches. Two of these samples are conditioned in each of 5 environments (all except 185F oven) and tested periodically. In each sample pair, one is oriented for axial heat flow, and the other is oriented for radial heat flow (relative to the package geometry). Thermal conductivity is measured at 2 mean temperatures -25 and 50C (77 and 122F) - for all samples, and is also measured at 85C (185F) for 185F and hotter aging environments.

Specific heat capacity samples are cylindrical, approximately 1 inch diameter and 1.5 inches high. Three of these samples are conditioned in each of 2 environments (250F oven and 185F 30\%RH chamber) and tested periodically. Specific heat capacity is measured for each of two mean temperatures -25 and 52C (77 and 125F). Of these two temperatures, 125F provides the more reliable results, with less scatter among multiple trials.

Conditioning of samples began in November 2008. Thermal and physical property samples were characterized before conditioning, and separate compression samples were tested without conditioning to document baseline behavior. The three oven environments have been maintained on an almost continuous basis, while the environmental chambers have experienced varying 
degrees of down-time. Therefore, the samples in the 185F 30\%RH environment have not accumulated as much total exposure time as the oven samples. The samples in the other humid environments, which began conditioning in early 2011, have accumulated even less time at temperature.

\section{$\underline{\text { Results }}$}

The physical property samples are measured on an approximately weekly basis. These data (for one of each pair of samples) are shown in Figure 1 on a normalized basis (each datum is divided by its corresponding value after the first conditioning period). This normalization allows for a direct comparison of degradation between samples with different starting values. The rates of change in the weight, density and dimensions of these samples are summarized in Table 1 for all samples. Rates of change for cane fiberboard samples over the same aging period are also shown in Table 1, for comparison.

Compression testing is performed with the load applied either parallel or perpendicular to the fiberboard layers. Typical stress-strain curves for softwood fiberboard samples tested in the parallel orientation are shown in Figure 2. Typical stress-strain curves for softwood fiberboard samples tested in the perpendicular orientation are shown in Figure 3.

Because of variation in the shape of the stress-strain curve from one sample to another, two metrics have been used to provide a comparison of compression test performance. For samples of both orientations, the area under the stress-strain curve up to a strain of $40 \%$ provides a metric that is roughly proportional to the energy absorbed by the material. In addition, samples tested in the parallel orientation experience an initial stress peak as the layers start to buckle. This buckling strength provides a second metric for comparison of the parallel orientation samples. These metrics are summarized in Figure 4, along with comparable data for cane fiberboard samples, for samples tested in the parallel orientation. The area under the stress-strain curve to a strain of $40 \%$ data are summarized in Figure 5, along with comparable data for cane fiberboard samples, for samples tested in the perpendicular orientation.

Thermal conductivity data for each sample are presented in Figure 6. Similar trends are seen for each of the three test temperatures $-25,50$ and 85C. Since the baseline thermal conductivity varies for each sample, normalized data are shown in Figure 7, and show the relative change from the first data point (after $\sim 8$ weeks conditioning). Comparable normalized data for typical cane fiberboard samples are also shown in Figure 7. A more complete comparison of thermal conductivity degradation rates for softwood and cane fiberboard samples is shown in Table 2.

Specific heat capacity results are summarized in Figure 8. Due to the degree of scatter in individual results, data from each trial for all 3 samples in a given environment are averaged for each conditioning period. Comparable data for cane fiberboard samples are also shown in Figure 8. 


\section{$\underline{\text { Discussion }}$}

No significant degradation has been observed in fiberboard assemblies from conforming packages (i.e. packages without excessive moisture and/or mold) examined following up to 7 years storage in KAMS. The typical package stored in KAMS contains a modest amount of moisture within the fiberboard assembly, and has an internal heat load significantly less than the 19 watt rating of the package. Most of the packages contain a cane fiberboard overpack assembly, although an increasing number contain softwood fiberboard (since cane fiberboard assemblies are no longer being produced).

The ambient temperature within KAMS can vary seasonally, or due to changes in HVAC status. However, for a typical summertime ambient temperature of $\sim 85^{\circ} \mathrm{F}$ and an internal heat load of 10 watts or less, the maximum fiberboard temperature is expected to be about $115^{\circ} \mathrm{F}$ for cane fiberboard. (This estimate is based on the $59^{\circ} \mathrm{F}$ increase from ambient to the maximum shield temperature calculated for a 19 watt heat load in Reference 6.) With softwood fiberboard, the maximum fiberboard temperature would be about 2-3 ${ }^{\circ} \mathrm{F}$ higher, based on Reference 7 . Within these packages, the warmer regions will tend to have lower moisture content, and the cooler regions will typically have slightly elevated moisture.

To date, all the packages removed from storage for destructive examination have contained cane fiberboard overpacks. They had been held in storage for periods ranging from $\sim 5$ months to 7 years. The consistent trend indicates the storage environment is sufficiently mild to preclude significant degradation over this time period, although baseline data from these specific cane fiberboard assemblies are not available for comparison. In contrast, the environments used for accelerated aging of the test samples described in this report are more severe than typical KAMS storage conditions. This difference is necessary in order to observe degradation and develop models for predicting service life in advance of unacceptable degradation occurring in KAMS.

Overall, similar aging trends are observed to date for softwood and cane fiberboard samples, with most properties in most of the aging environments degrading at essentially the same rate for both softwood and cane fiberboard. When differences occur between the two materials, the softwood fiberboard properties degrade faster than those of cane fiberboard in the elevated humidity environments, and the cane fiberboard properties degrade faster in the higher temperature dry environments. The previous softwood fiberboard status report [8] also observed some differences in the degradation rates between softwood and cane fiberboard, but the trends were not as clear at that time. Table 3 identifies several properties for which softwood fiberboard has degraded faster in one or more of the elevated humidity environments. Table 3 also identifies several properties for which cane fiberboard has degraded faster in the 250F dry environment. Performance is similar in the remaining environment / property combinations.

The compression test data (area under the curve up to $40 \%$ strain, parallel orientation) show softwood fiberboard degrading faster than cane fiberboard in two environments (160F 50\%RH and $185 \mathrm{~F} 30 \% \mathrm{RH})$. In addition, the buckling strength is degrading faster for softwood fiberboard than for cane fiberboard in the $185 \mathrm{~F} 30 \% \mathrm{RH}$ environment. For each of these cases, the comparison is incomplete, since material from some of the weaker cane fiberboard source packages was not aged 
and tested in these environments beyond 8-16 weeks duration. With some scatter in these data over a short time frame, extrapolation is not reliable.

In analyzing the cane fiberboard data [9], a model has been developed for the mechanical behavior (area under the stress-strain curve up to $40 \%$ strain, parallel orientation) based on the projected trend for the limiting cane fiberboard source package (Table 4). For the elevated humidity environments, the curves fit to the data for several source packages had a positive slope due to the scatter - i.e. the trend was for no degradation - and these cases therefore were not used in developing the aging model. For this reason, as well as the limited duration data cited above, the cane fiberboard aging model may not capture the behavior of the weaker cane fiberboard source packages. Therefore, the mechanical behavior of softwood fiberboard is not reliably described by the cane fiberboard model. At the present time, the decrease in energy absorption of softwood fiberboard is under-predicted (non-conservative) by the cane fiberboard model for elevated humidity environments, and over-predicted (conservative) by the cane fiberboard model for higher temperature dry environments. Nevertheless, the present data suggest that both cane and softwood fiberboard assemblies in conforming packages should perform satisfactorily for up to 15 years storage under typical conditions in KAMS.

Reference 9 recognized the need for an improved understanding of the environment within the 9975 drum in storage, and identified one measure that could help in this regard. This and/or other related actions would provide a better basis for application of aging models to both cane and softwood fiberboard.

Variation has been seen in the properties of cane fiberboard, as illustrated in the comparative data shown in Table 1 (physical properties), Table 2 (thermal conductivity) and Table 4 (compression strength). This reflects the inherent variability of this heterogeneous material. One would also expect variability in the properties of softwood fiberboard, although softwood fiberboard appears to be more consistent in its range of fiber size and overall texture. For the current task, all softwood fiberboard samples were obtained from a single assembly, and do not provide any indication of the degree of variation that might exist in other assemblies.

Previous baseline testing [10] provides some indication of variation in softwood fiberboard properties. Baseline softwood fiberboard samples were tested from material laminated by KnightCelotex at their Danville and Marrero plants. The metrics for these baseline samples indicate this material is weaker and absorbed less energy than the un-aged samples from the current effort. Therefore, the strength of softwood fiberboard used in the current effort may be stronger than average (considering a range of behaviors across multiple packages). Since the compression strength of un-aged softwood fiberboard from the current effort is similar on average to that of cane fiberboard, it appears that other softwood fiberboard assemblies may be weaker, on average, than cane fiberboard. It is recommended that softwood fiberboard samples from additional assemblies be tested (with and without aging) when they become available.

\section{Conclusions}

Overall, similar aging trends are observed for softwood and cane fiberboard samples, with a few differences. There are modest differences between the two materials in several properties 
following aging in some of the environments. Where differences are seen, the softwood fiberboard degrades faster in elevated humidity environments, while cane fiberboard degrades faster in higher temperature dry environments. As a result, it is premature to assume both materials will age at the same rates, and the preliminary aging models developed for cane fiberboard might not apply to softwood fiberboard. However, it is expected that both cane and softwood fiberboard assemblies will perform satisfactorily in conforming packages stored in a typical KAMS environment for up to 15 years.

The softwood fiberboard data collected to date show less sample-to-sample variation in physical properties than cane fiberboard, although this test effort includes softwood fiberboard samples from a single package only. Aging and testing of the remaining softwood fiberboard samples will continue.

The limited source for softwood fiberboard material to date provides little data to understand the range of scatter that might be inherent in this material. Data from additional softwood fiberboard assemblies should be obtained as the material becomes available.

\section{References}

[1] WSRC-STI-2008-00329, "Review of Data Comparing Softwood Fiberboard and Cane Fiberboard Properties Relevant to 9975 Shipping Packages”, W.L. Daugherty, June 2008.

[2] WSRC-TR-2008-00024, "Task Technical and Quality Assurance Plan for Testing to Support Acceptance into KAMS of Model 9975 Packages with Softwood Fiberboard Overpack (U)”, January 2008.

[3] WSRC-TR-2001-0286, Rev. 2, "SRS Surveillance Program for Storage of Pu Material in KAMS”.

[4] PVP2007-26114, "Properties of Fiberboard Overpack Material in the 9975 Shipping Package following Thermal Aging”, W. L. Daugherty, Proceedings of PVP 2007 Conference, July 2007, ASME.

[5] WSRC-STI-2006-00121, "Degradation of Fiberboard in Model 9975 Package Following Environmental Conditioning - First Interim Report”, W. L. Daugherty and S. P. Harris, May 2007.

[6] M-CLC-K-00727, "Thermal Model Study for the 9975 Package in KAMS During Facility Fire”, N.K. Gupta, June 11, 2008.

[7] M-CLC-K-00729, "Thermal Analysis of the 9975 Package with Softwood-Based Fiberboard during KAMS Facility Fire”, N. K. Gupta, June 11, 2008.

[8] SRNL-TR-2011-00327, "Third Status Report: Testing of Aged Softwood Fiberboard Material for the 9975 Shipping Package”, W. L. Daugherty, December 2011. 
[9] SRNL-STI-2013-00020, "Status Report - Cane Fiberboard Properties and Degradation Rates for Storage of the 9975 Shipping Package in KAMS”, W. L. Daugherty, January 2013.

[10] SRNL-MST-2008-00043, "Properties of Un-Aged Knight-Celotex Softwood Fiberboard for Thermal Modeling”, W. L. Daugherty, February 27, 2008.

Table 1. Physical property changes in softwood (2 samples) vs cane fiberboard (range of 5 - 8 samples per environment) over the stated aging period. Rates of change for softwood fiberboard are in bold if they are more than $0.25 \% / y r$ outside the range observed for cane fiberboard samples.

\begin{tabular}{|c|c|c|c|c|}
\hline & & & Softwood Fiberboard & Cane Fiberboard \\
\hline Property & Environment & $\begin{array}{l}\text { Aging Period } \\
\text { (days) }\end{array}$ & $\begin{array}{l}\text { Rate of Change } \\
(\% / \mathrm{yr})\end{array}$ & $\begin{array}{l}\text { Rate of Change } \\
\text { (\%/yr) }\end{array}$ \\
\hline \multirow[t]{6}{*}{$\overline{~ W e i g h t ~}$} & $250 \mathrm{~F}, \mathrm{dry}$ & 1234 & $-11.68,-11.42$ & -14.56 to -12.43 \\
\hline & 215F, dry & 1380 & $-3.34,-3.19$ & -3.77 to -2.99 \\
\hline & 185F, dry & 1481 & $-1.20,-1.19$ & -1.16 to -0.87 \\
\hline & 185F, 30\%RH & 1071 & $-5.80,-5.69$ & -4.65 to -3.48 \\
\hline & 160F, 50\%RH & 639 & $-3.70,-3.62$ & -4.53 to -2.79 \\
\hline & 125F, 70\%RH & 699 & $-1.16,-1.14$ & -0.68 to -0.24 \\
\hline \multirow[t]{6}{*}{ Density } & 250F, dry & 1234 & -6.50,-5.53 & -8.34 to -7.06 \\
\hline & 215F, dry & 1380 & $-1.09,-0.92$ & -1.70 to +0.03 \\
\hline & 185F, dry & 1481 & $-0.23,-0.08$ & -0.55 to +0.54 \\
\hline & $185 \mathrm{~F}, 30 \% \mathrm{RH}$ & 1071 & $-3.06,-2.99$ & -2.27 to -1.17 \\
\hline & 160F, 50\%RH & 639 & $-1.92,-1.59$ & -1.79 to -1.08 \\
\hline & $125 \mathrm{~F}, 70 \% \mathrm{RH}$ & 699 & $-0.32,-0.27$ & -0.13 to +0.24 \\
\hline \multirow[t]{6}{*}{$\bar{~}$ Height } & 250F, dry & 1234 & $-5.07,-4.56$ & -6.28 to -3.59 \\
\hline & 215F, dry & 1380 & $-1.56,-1.41$ & -1.51 to -1.12 \\
\hline & 185F, dry & 1481 & $-0.66,-0.52$ & -0.60 to -0.37 \\
\hline & $185 \mathrm{~F}, 30 \% \mathrm{RH}$ & 1071 & $-1.84,-1.77$ & -1.78 to -1.28 \\
\hline & $160 \mathrm{~F}, 50 \% \mathrm{RH}$ & 639 & $-1.49,-1.17$ & -1.70 to -1.14 \\
\hline & 125F, 70\%RH & 699 & $-0.36,-0.30$ & -0.31 to -0.04 \\
\hline \multirow{6}{*}{$\begin{array}{l}\text { Length, } \\
\text { Width }\end{array}$} & $250 \mathrm{~F}$, dry & 1234 & -1.97 to -0.90 & -3.39 to -1.04 \\
\hline & 215F, dry & 1380 & -0.54 to -0.38 & -1.40 to -0.33 \\
\hline & 185F, dry & 1481 & -0.25 to -0.22 & -0.53 to -0.06 \\
\hline & 185F, 30\%RH & 1071 & -0.82 to -0.56 & -0.60 to -0.34 \\
\hline & $160 \mathrm{~F}, 50 \% \mathrm{RH}$ & 639 & -0.44 to -0.28 & -0.67 to -0.35 \\
\hline & $125 \mathrm{~F}, 70 \% \mathrm{RH}$ & 699 & -0.34 to -0.14 & -0.29 to -0.04 \\
\hline
\end{tabular}


Table 2. Thermal conductivity (at 25C) changes in softwood (1 sample per environment / orientation) vs cane fiberboard (range of 1 - 4 samples per environment / orientation) over the stated aging period. Rates of change for softwood fiberboard are in bold if they are more than 0.25 $\% / y r$ outside the range observed for cane fiberboard samples.

\begin{tabular}{|c|c|c|c|c|}
\hline & & & Softwood Fiberboard & Cane Fiberboard \\
\hline Orientation & Environment & $\begin{array}{l}\text { Aging Period } \\
\text { (weeks) }\end{array}$ & $\begin{array}{l}\text { Rate of Change } \\
\text { (\%/yr) }\end{array}$ & $\begin{array}{l}\text { Rate of Change } \\
\text { (\%/yr) }\end{array}$ \\
\hline \multirow[t]{5}{*}{ Axial } & 250F, dry & 185 & -5.26 & -7.56 to -7.08 \\
\hline & 215F, dry & 180 & -2.09 & -2.26 to -1.91 \\
\hline & $185 \mathrm{~F}, 30 \% \mathrm{RH}$ & 135 & -3.28 & -3.27 to -2.52 \\
\hline & 160F, 50\%RH & 80 & -3.59 & -2.20 to -1.05 \\
\hline & 125F, 70\%RH & 96 & -0.43 & -1.10 to +0.41 \\
\hline \multirow[t]{5}{*}{ Radial } & 250F, dry & 185 & -8.28 & -10.77 to -9.32 \\
\hline & 215F, dry & 180 & -2.48 & -2.55 to -1.95 \\
\hline & $185 \mathrm{~F}, 30 \% \mathrm{RH}$ & 135 & -2.98 & -3.59 to -2.26 \\
\hline & 160F, 50\%RH & 80 & -3.74 & -2.83 to -0.82 \\
\hline & 125F, 70\%RH & 96 & +0.81 & +1.05 \\
\hline
\end{tabular}


Table 3. Comparison of softwood and cane fiberboard behavior. The listing of one material indicates that material degraded significantly faster for the particular environment and property.

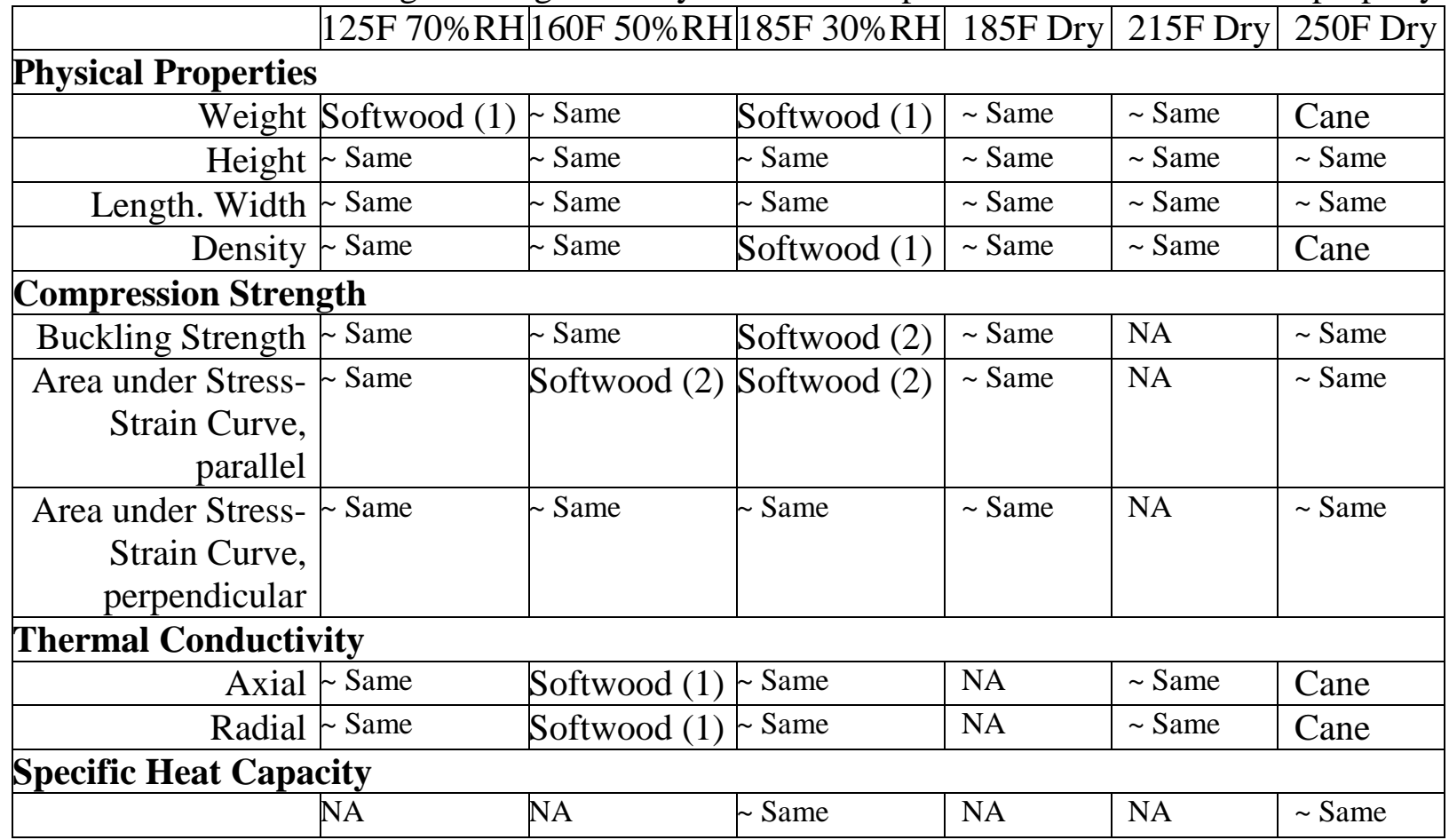

Softwood (1) - Softwood samples degrading faster than cane samples

Softwood (2) - Softwood samples degrading faster than cane samples (but weakest cane package not aged/tested in this environment)

Cane - Cane samples degrading faster than softwood samples

Table 4. Extrapolated estimates of the time for the area under the stress-strain curve up to $40 \%$ strain for parallel orientation samples to degrade to 11 psi. Estimates are based on an exponential fit to the data for each source package.

\begin{tabular}{|c|c|c|c|c|c|c|c|}
\hline & $\begin{array}{c}125 \mathrm{~F}, \\
70 \%\end{array}$ & $\begin{array}{c}160 \mathrm{~F}, \\
50 \%\end{array}$ & $\begin{array}{l}185 \mathrm{~F}, \\
30 \%\end{array}$ & $\begin{array}{c}\text { 125F, } \\
\text { dry }\end{array}$ & $\begin{array}{c}\begin{array}{c}185 F \\
\text { dry }\end{array}\end{array}$ & $\begin{array}{c}215 \mathrm{~F}, \\
\text { dry }\end{array}$ & $\begin{array}{c}250 \mathrm{~F}, \\
\text { dry }\end{array}$ \\
\hline \multicolumn{8}{|c|}{ Softwood fiberboard- time to degrade to $11 \mathrm{psi}$, (yrs) } \\
\hline & 5.33 & 1.14 & 1.15 & - - & 16.56 & - - & 1.85 \\
\hline \multicolumn{8}{|c|}{ Cane fiberboard [9] - time to degrade to $11 \mathrm{psi}$, yrs } \\
\hline LD1 & + slope * & + slope $*$ & 1.88 & 6.9 & 11.0 & 4.5 & 1.67 \\
\hline LD2 & $2.3 *$ & + slope $*$ & -- & + slope & 19.5 & 7.7 & 1.06 \\
\hline MSC & $1.5 *$ & + slope * & 2.00 & 43.2 & 76.9 & 2.7 & 1.69 \\
\hline New & + slope & 4.98 & 3.29 & - - & + slope & - - & 1.04 \\
\hline
\end{tabular}

* Data for these source packages in these environments is limited to a maximum of 8 - 16 weeks exposure. Extrapolation from this short range is not considered reliable. 


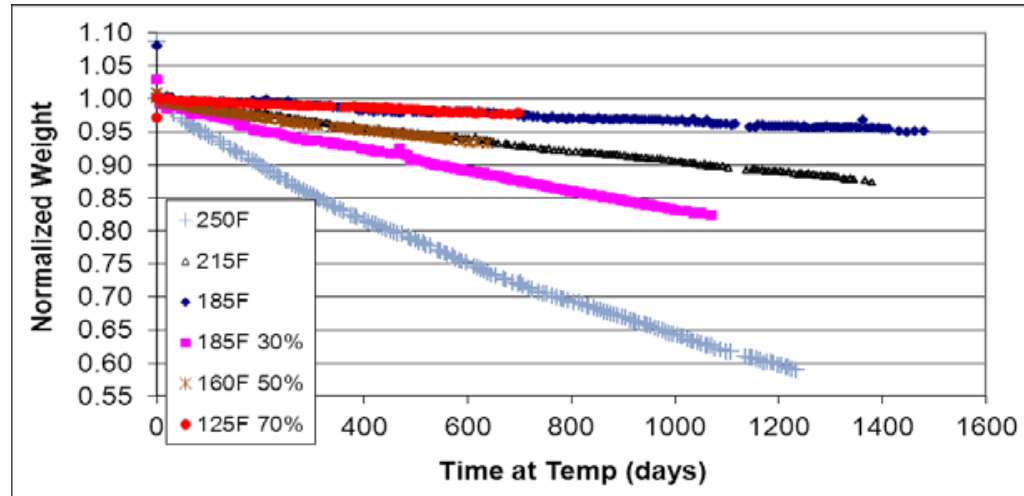

Figure 1. Normalized data for softwood fiberboard physical property samples.

(a) Weight change

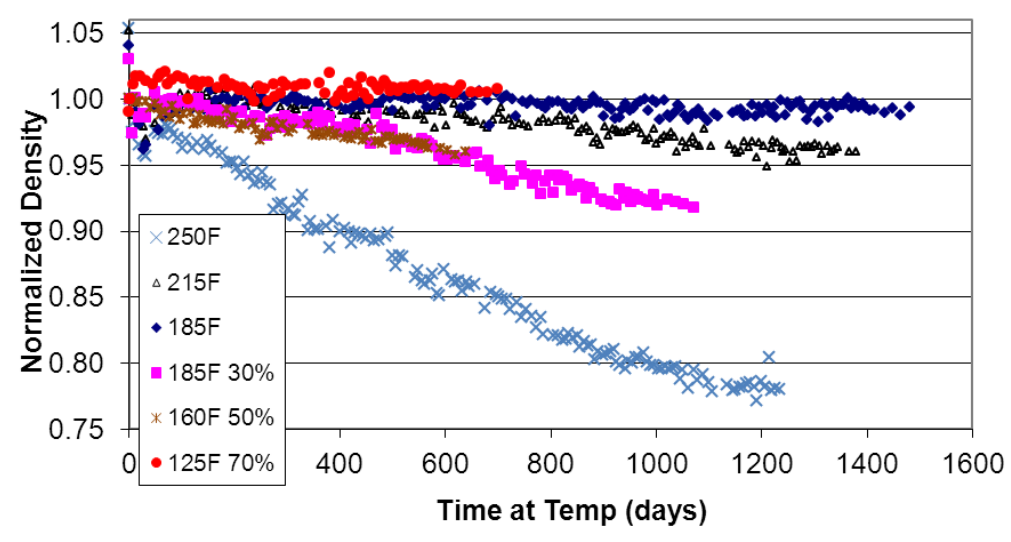

(b) Density change

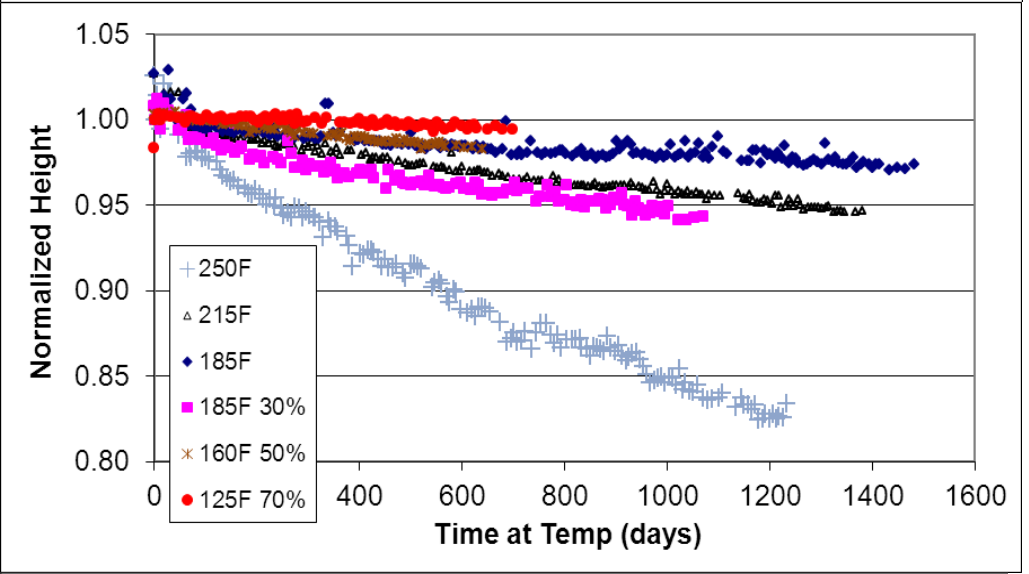

(c) Height change

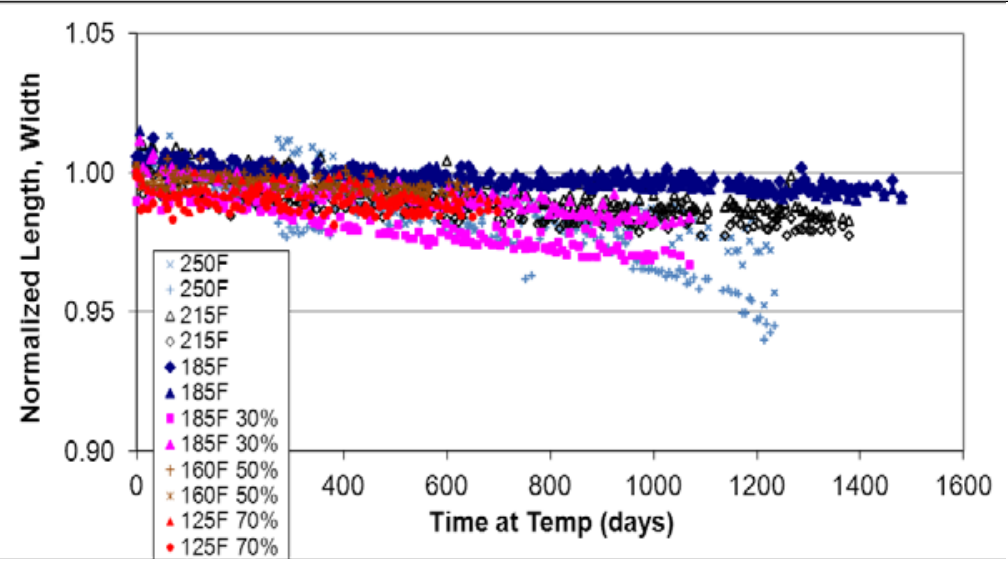

(d) Length / width change 

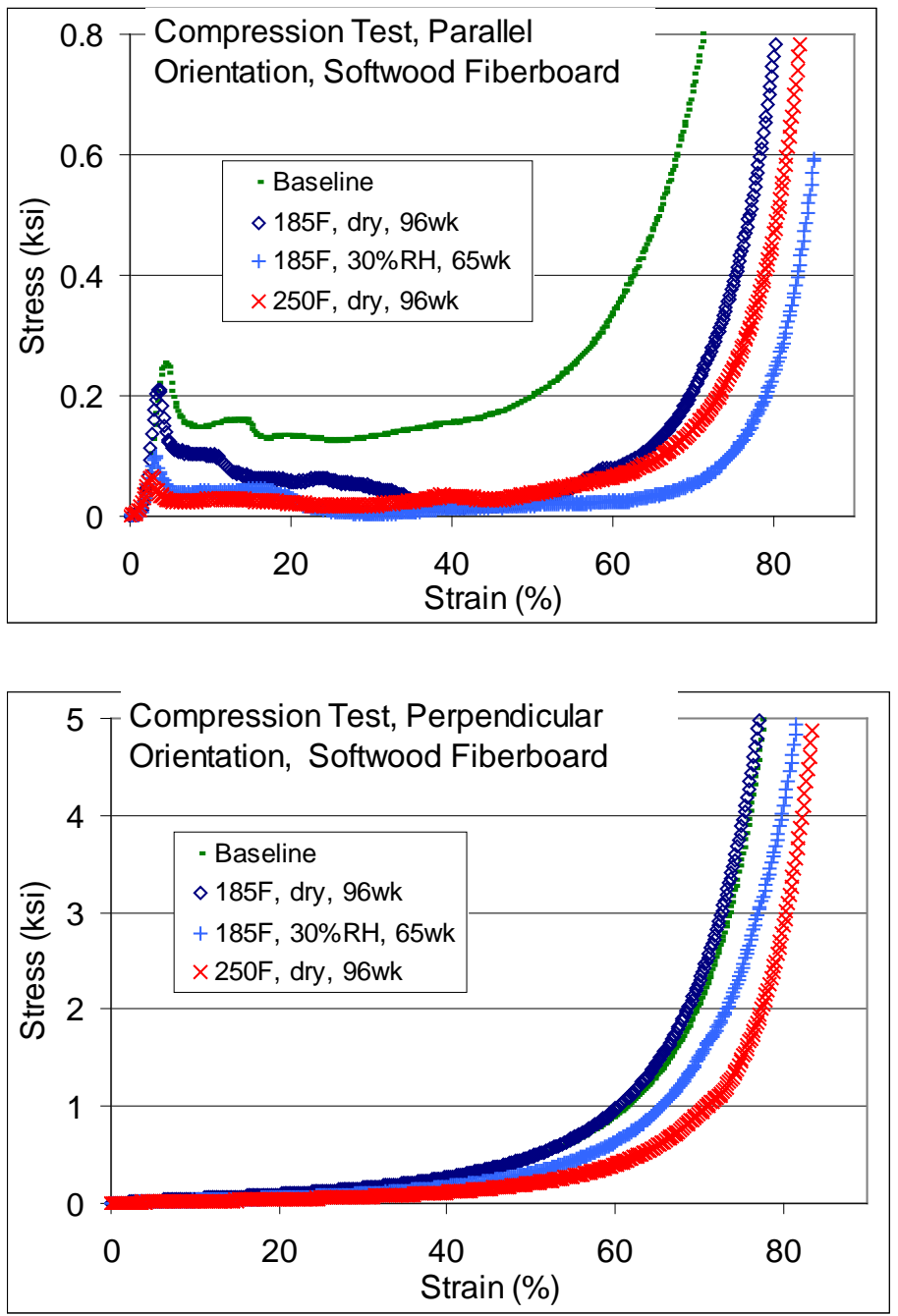

Figure 2. Typical compression stress-strain curves for softwood fiberboard samples, parallel orientation
Figure 3. Typical compression stress-strain curves for softwood fiberboard samples, perpendicular orientation 

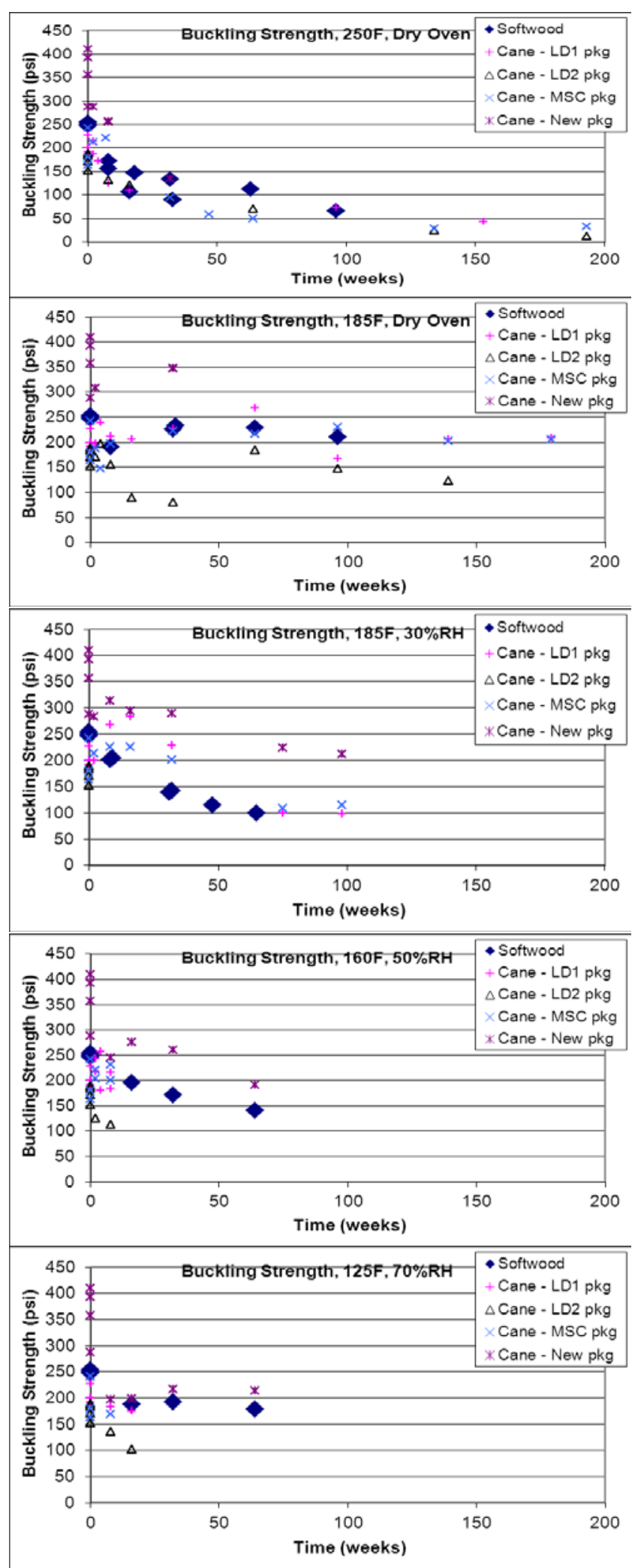
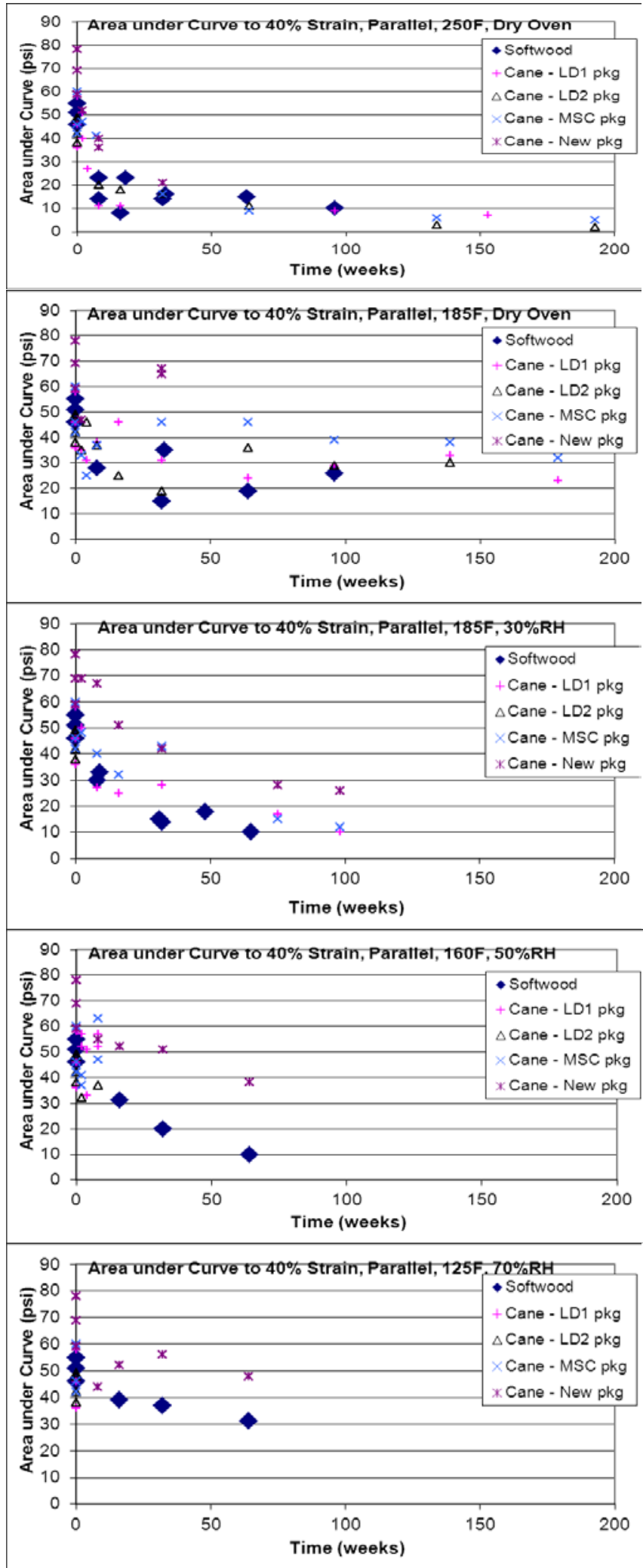

Figure 4. Compression test metrics (buckling strength, area under curve to $40 \%$ strain) for parallel orientation samples. 

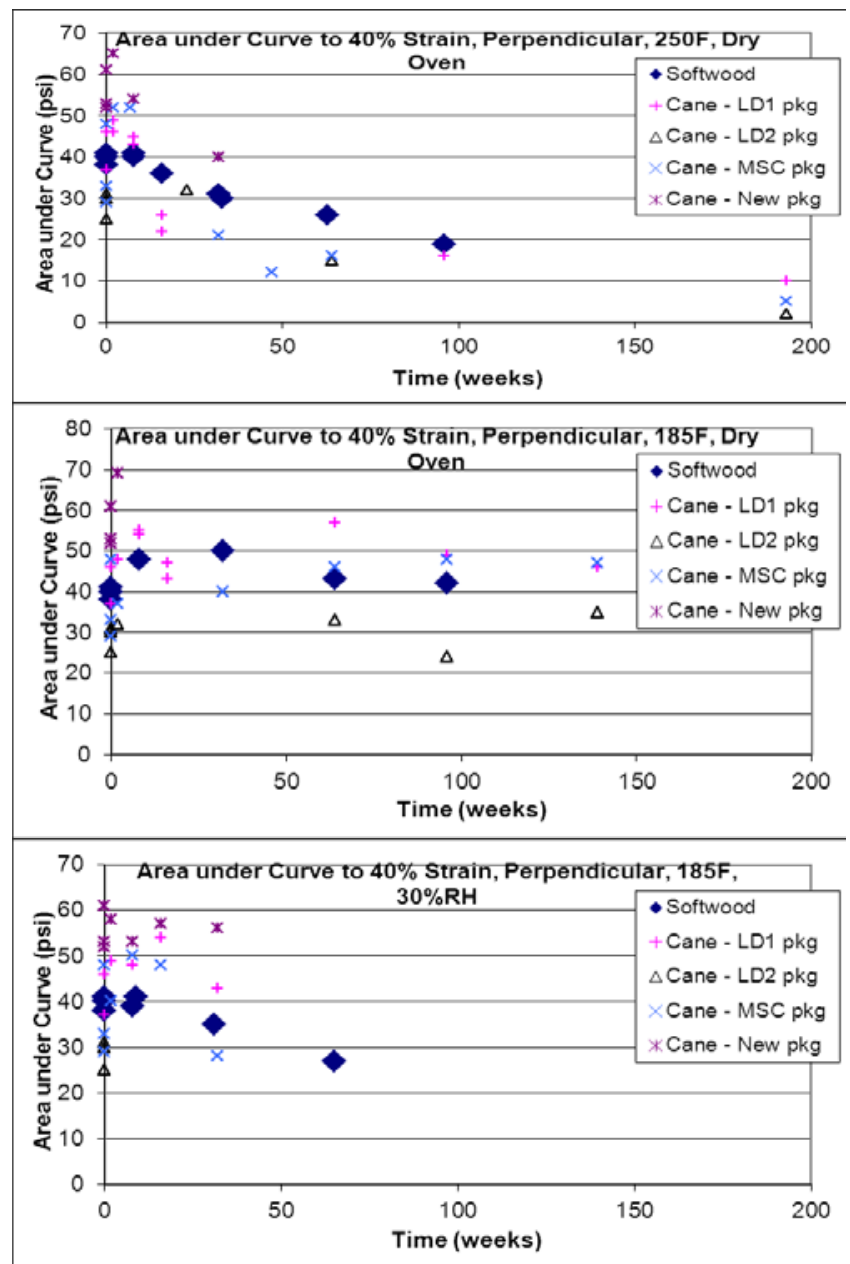

Figure 5. Compression test metric (area under curve to $40 \%$ strain) for perpendicular orientation samples.
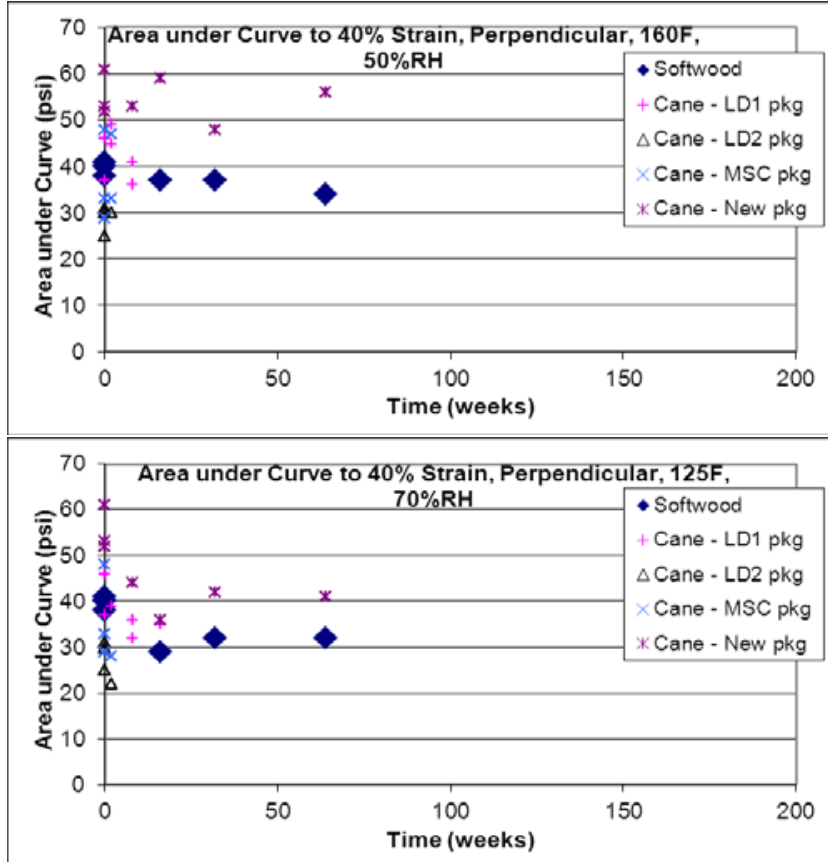


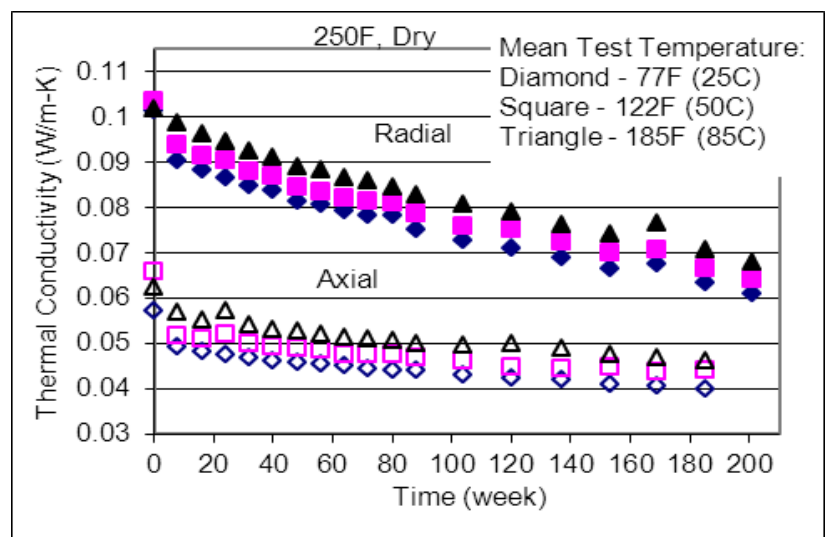

(a) 250F oven

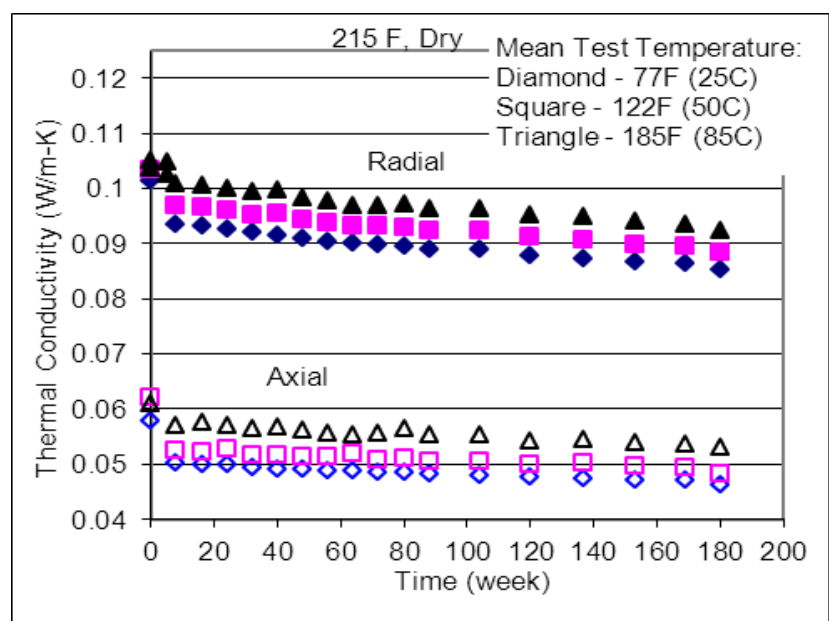

(b) $215 \mathrm{~F}$ oven

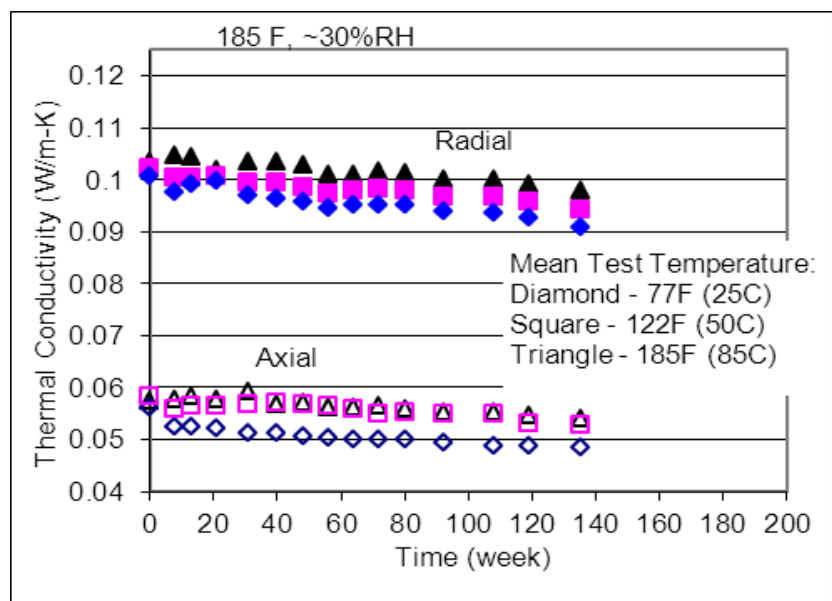

(c) $185 \mathrm{~F} 30 \% \mathrm{RH}$ chamber
Figure 6. Thermal conductivity data for softwood fiberboard samples conditioned in the indicated environments

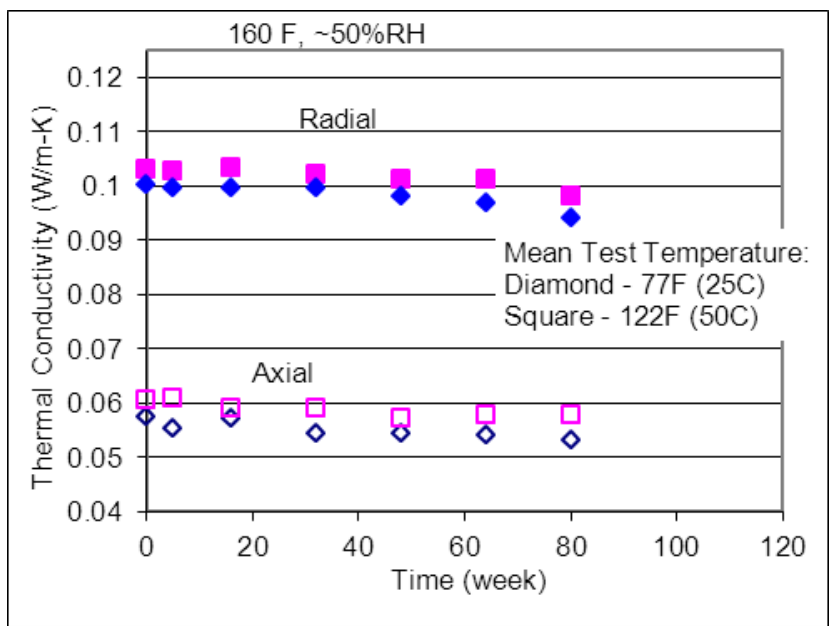

(d) $160 \mathrm{~F} 50 \% \mathrm{RH}$ chamber

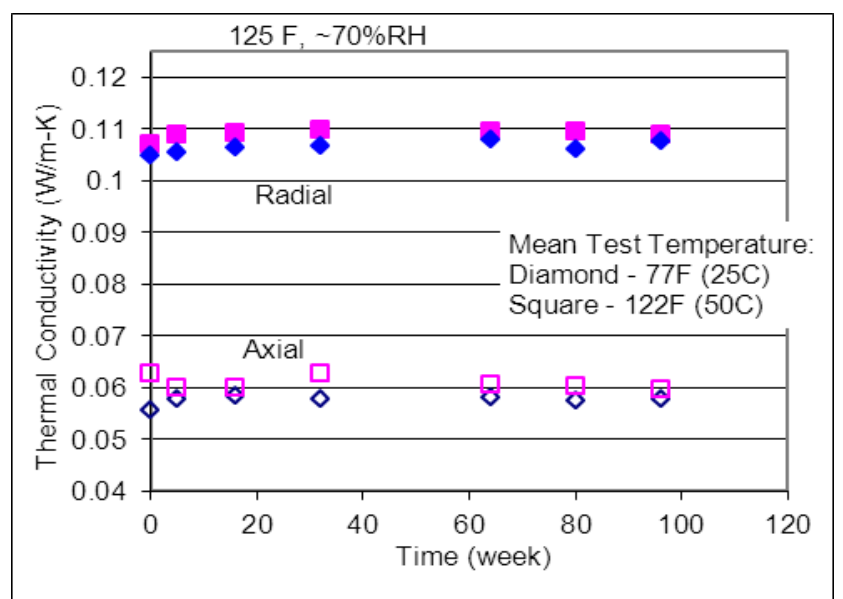

(e) $125 \mathrm{~F} 70 \% \mathrm{RH}$ chamber 


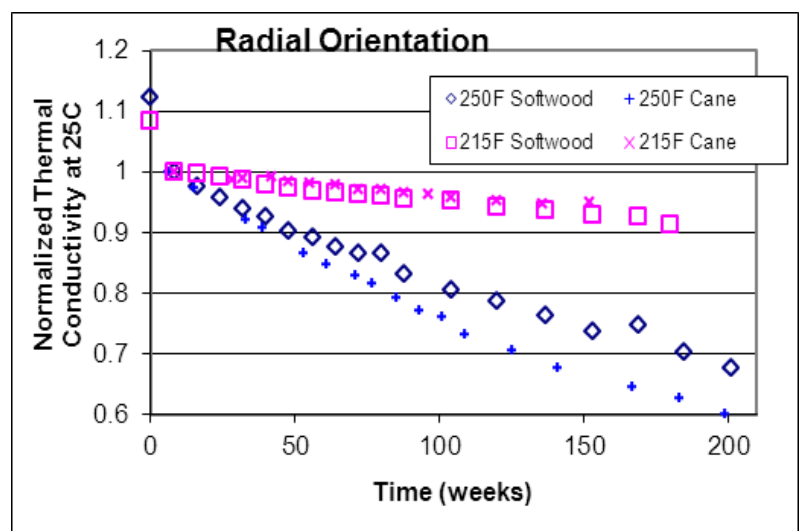

(a) radial orientation, dry oven environments

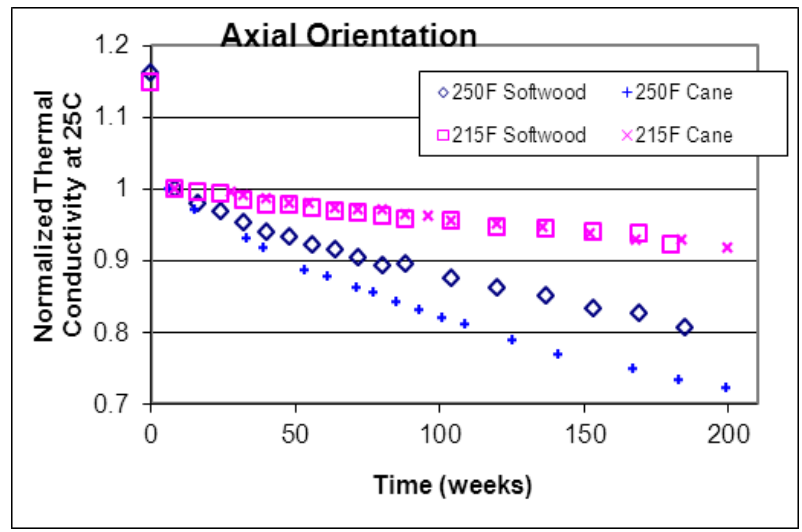

(c) axial orientation, dry oven environments

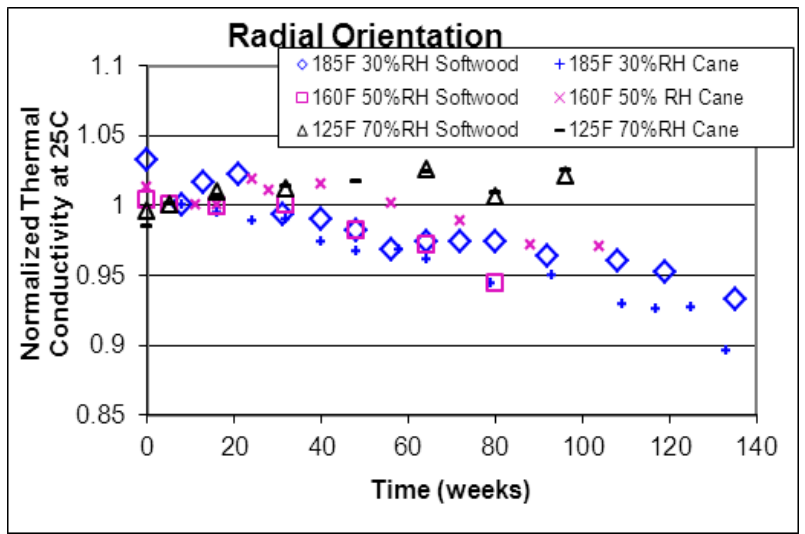

(b) radial orientation, humid environments

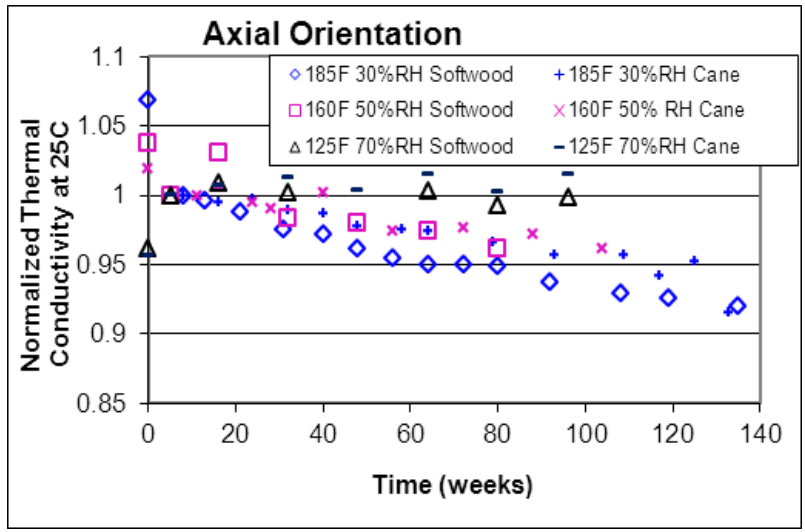

(d) axial orientation, humid environments

Figure 7. Normalized thermal conductivity data for softwood fiberboard compared to typical data for cane fiberboard. A more complete comparison of softwood and cane fiberboard thermal conductivity degradation rates is provided in Table 2.

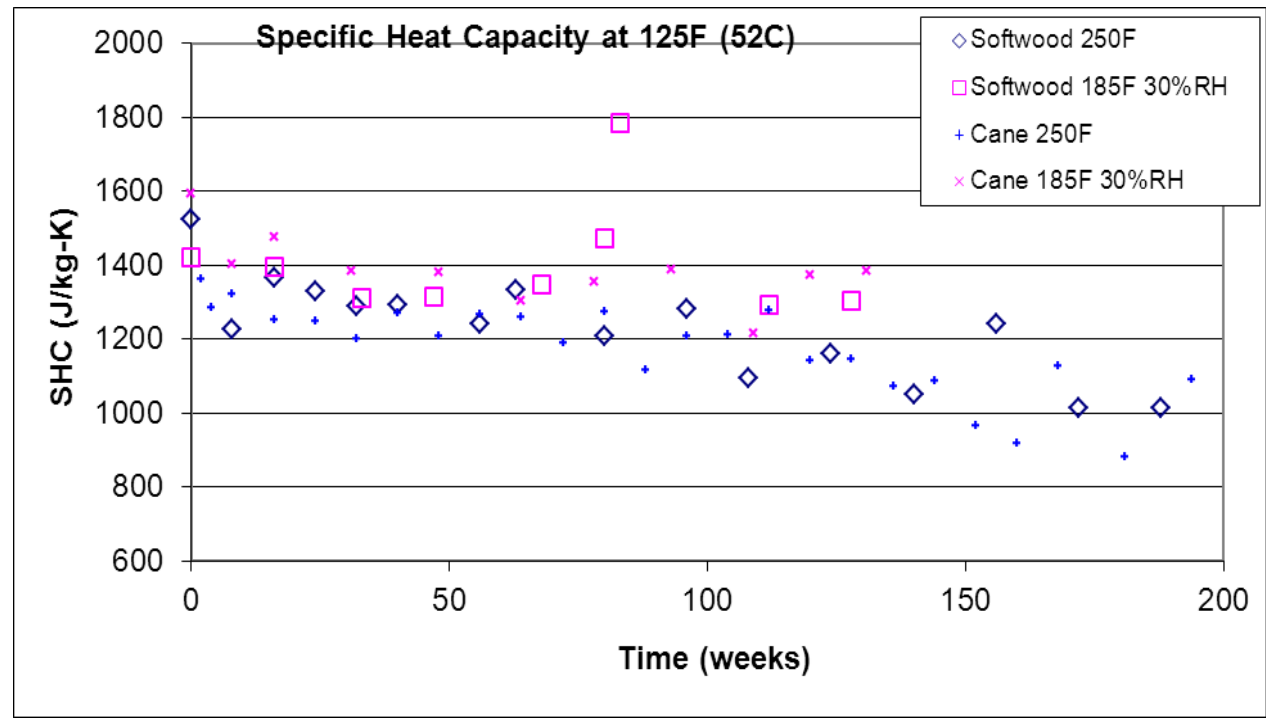

Figure 8. Specific heat capacity data for softwood fiberboard at a mean temperature of 52C, compared with cane fiberboard 
CC: J. S. Bellamy, 730-A

G. T. Chandler, 773-A

W. L. Daugherty, 773-A

K. A. Dunn, 773-41A

L. F. Gelder, 730-A

T. W. Griffin, 705-K

E. R. Hackney, 705-K

D. R. Leduc, 730-A

J. W. McEvoy, 707-C

D. L. Melvin, 705-K

T. E. Skidmore, 730-A

K. E. Zeigler, 773-41A

Document Control 